\title{
Modulation of Spinal Motor Output by Initial Arm Postures in Anesthetized Monkeys
}

\author{
Hiroaki Yaguchi, ${ }^{1,2}$ Tomohiko Takei, ${ }^{1}$ David Kowalski, ${ }^{3}$ Takafumi Suzuki, ${ }^{4}$ Kunihiko Mabuchi, ${ }^{2}$ and Kazuhiko Seki ${ }^{1,5}$ \\ ${ }^{1}$ Department of Neurophysiology, National Institute of Neuroscience, Tokyo 187-8502, Japan, ${ }^{2}$ Graduate School of Information Science and Technology, \\ The University of Tokyo, Tokyo 113-8656, Japan, ${ }^{3}$ School of Biomedical Engineering, Science and Health Systems, Drexel University, Philadelphia, \\ Pennsylvania 19104, ${ }^{4}$ Center for Information and Neural Networks, National Institute of Information and Communications Technology, Osaka 565-0871, \\ Japan, and ${ }^{5}$ Precursory Research for Embryonic Science and Technology, Japan Science and Technology Agency, Saitama 332-0012, Japan
}

Proper execution of voluntary movement requires a sensorimotor transformation based on the initial limb state. For example, successfully reaching to a stable target requires the recruitment of different muscle groups depending on limb position at movement initiation. To test whether this transformation could occur at the spinal level, we stimulated the cervical spinal cord of anesthetized monkeys while systematically changing initial posture and examined the modulation of the twitch response induced in the upper limb muscles. In three monkeys, a multichannel microelectrode array was implanted into the $\mathrm{C} 6$ segment of the spinal cord and electromyographic electrodes were implanted in 12 limb muscles (five hand, four elbow, and three shoulder muscles). The magnitude and onset latency of the evoked response in each electrode-muscle pair were examined by systematically changing the hand position through nine positions in a horizontal plane with the monkey prone. Among 330 electrode-muscle pairs examined, $61 \%$ of pairs exhibited significant modulation of either magnitude or latency of twitch responses across different hand/arm configurations (posture dependency). We found that posture dependency occurred preferentially in the distal rather than proximal muscles and was not affected by the location of the electrode within the stimulated spinal segment. Importantly, this posture dependency was not affected by spinalization at the C2 level. These results suggest that excitability in the cervical spinal cord is affected by initial arm posture through spinal reflex pathways. This posture dependency of spinal motor output could affect voluntary arm movement by adjusting descending motor commands relative to the initial arm posture.

Key words: arm posture; EMG; microstimulation; monkey; spinal cord; twitch

\section{Introduction}

The proper execution of voluntary movement requires information about the initial effector state. Although the final movement goal may be the same, different motor programs need to be executed depending on the initial limb posture. For example, a reaching movement toward a specific target will recruit different muscle groups, depending on the arm position at movement

Received Sept. 8, 2014; revised March 19, 2015; accepted March 23, 2015.

Author contributions: H.Y., T.T., D.K., and K.S. designed research; H.Y., T.T., D.K., and K.S. performed research; H.Y., T.T., and D.K. contributed unpublished reagents/analytic tools; H.Y., T.T., and K.S. analyzed data; H.Y., T.T., D.K., T.S., K.M., and K.S. wrote the paper.

This work was supported by grants-in-aid for scientific research on priority areas Mobilligence (Grant 18020030) and System Study on Higher-Order Brain Function (Grant 18047027) and on innovative area Understanding Brain Plasticity on Body Representations to Promote their Adaptive Functions (Grant 26120003) from the Ministry of Education, Culture, Sports, Science and Technology of Japan (K.S.) and the Japan Science and Technology Agency Precursory Research for Embryonic Science and Technology program (K.S.). D.K. was a Japan Society for the Promotion of Science summer fellow and supported by National Science Foundation Grant OISE-1108063. We thank C. Sasaki for technical assistance, Michel Lemay for lending the multiaxis force sensor, and Jonas Zimmermann for helping with some surgery and recording.

The authors declare no competing financial interests.

Correspondence should be addressed to Kazuhiko Seki, PhD, Department of Neurophysiology, National Institute of Neuroscience, 4-1-1 Ogawa-Higashi, Kodaira, Tokyo 187-8502, Japan. E-mail: seki@ncnp.go.jp

T. Takei's present address: Center for Neuroscience Studies, Queen's University, Kingston, Ontario K7L 3N6, Canada.

DOI:10.1523/JNEUROSCI.3846-14.2015

Copyright $\odot 2015$ the authors $\quad 0270-6474 / 15 / 356937-09 \$ 15.00 / 0$ onset. When the right arm is placed on the left side of a target, finger, wrist, and elbow extensor muscles are mainly recruited to approach it. In contrast, flexor muscles are recruited when reaching from the right side of a target. It is not fully understood how the CNS recruits and adjusts motor commands corresponding to the infinitely variable initial state of the arm and hand.

This initial state could be first sensed implicitly by proprioceptors and skin receptors (Stein et al., 2004; Umeda et al., 2012), and the ensemble activity of primary afferents from these receptors could be represented as a local change in limb state by integrating them within the CNS (Bosco and Poppele, 2001). Upon voluntary movement onset, the initial state represented by this integrated information needs to interact with motor commands to allow the selection and control of the spatiotemporal activity of appropriate muscles under different initial limb postures. This integration may occur at various relays within the CNS (Scott, 2004). As proposed earlier (Grillner, 2006), the spinal cord can be regarded as both the initial and final stages for this integration because of its proximity to the periphery. Different patterns of spinal reflexes induced in the contralateral limb dependent on their initial posture (Grillner and Rossignol, 1978) suggest that this mechanism is not limited to a single limb. The neural mechanism responsible for this integration, however, has not been established. 
A

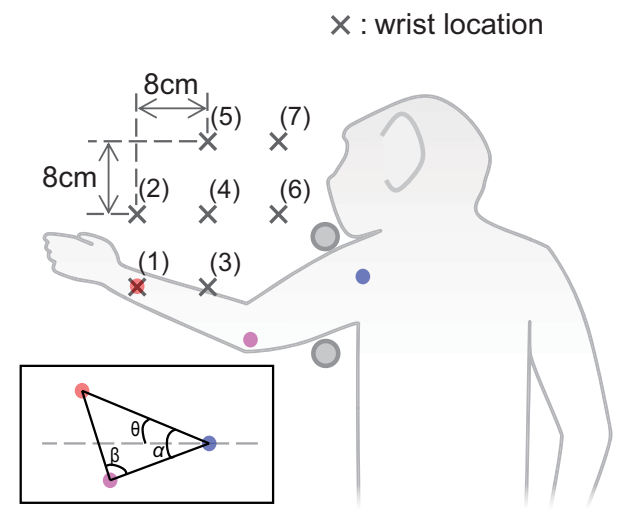

B

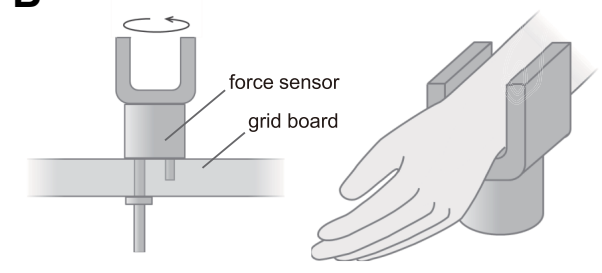

C
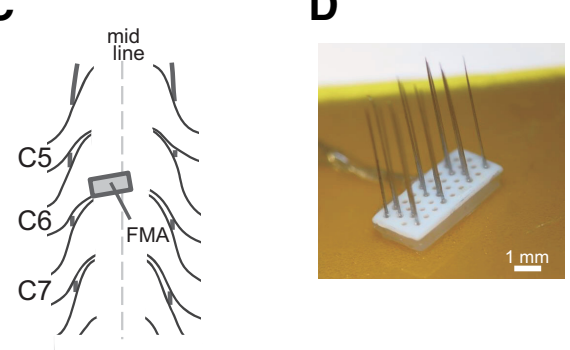

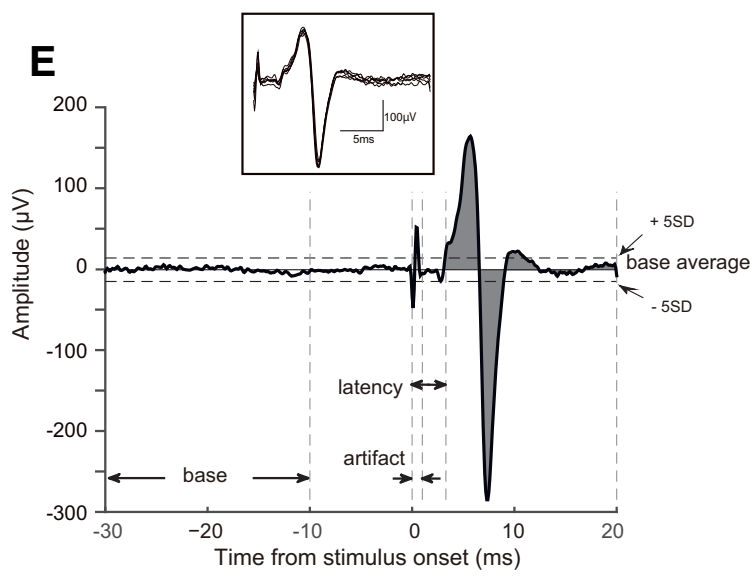

Figure 1. Experimental procedure and EMG analysis. $A$, A monkey was anesthetized and laid prone on a horizontal table. The posture of the left limb was changed by fixing the left wrist at one of the seven points on a square grid of $8 \mathrm{~cm}$ intervals $(\boldsymbol{A}$, crosses). The shoulder was stabilized with two vertical poles (gray circles). The number designations of the postures are shown in parentheses. Red, pink, and blue dots represent the landmark points of the wrist, elbow, and shoulder joints, respectively. The joint angles of the shoulder $(\alpha)$ and elbow $(\beta)$, and that between the shoulder and wrist $(\theta)$ were measured in each animal and are listed in Table $1 . \boldsymbol{B}$, The wrist was fixed to each point by a swiveling U-shape hand holder with an integrated force sensor. $\boldsymbol{C}$, A microelectrode array was implanted in the 66 level of the spinal cord. The schema shows the placement of the microelectrode array in monkey TE in the dorsal view. $\boldsymbol{D}$, The microelectrode array used for monkey TE. $\boldsymbol{E}$, Measurement of EMG responses. The EMG response was averaged over the trials in each posture; then base average and SD were calculated. Onset was identified at the time point when the signal crossed the $\pm 5 \mathrm{SD}$ of the base signal. Onset latency was measured relative to the stimulus onset. Area of response was measured as an integrated amplitude from 1 or 3 to $20 \mathrm{~ms}$ after the stimulus onset. Overlay display of original traces without averaging of this response is shown in an inset. For this response, mean area was $813 \pm 21.1 \mu \mathrm{Vms}$ and onset latency was $3.9 \pm 0.3 \mathrm{~ms}$.

Spinal interneurons (INs), which are located mainly in the intermediate zone of gray matter, receive projections from a majority of descending tracts, including corticospinal (Ralston and Ralston, 1985; Morecraft et al., 2013), reticulospinal (Holstege and Kuypers, 1982), and rubrospinal (Holstege and Tan, 1988). These INs also receive convergent input from peripheral afferents with different modalities and receptive fields (Lundberg and Voorhoeve, 1962; Lundberg et al., 1962; Baldissera et al., 1981; Jankowska, 1992; Hultborn, 2006). Importantly, they are active in the preparation and execution of voluntary movement, suggesting their crucial role (Perlmutter et al., 1998; Prut and Fetz, 1999; Takei and Seki, 2010, 2013). Therefore, it is reasonable to hypothesize that the initial limb configuration is represented and integrated into volitional motor commands in the spinal INs through the convergent nature of their input.

Here, we applied intraspinal microstimulation (ISMS) and recorded the evoked twitch responses using electromyography (EMG) to test this hypothesis. Single-pulse microstimulation activates neurons and fibers located within a limited radius around the stimulus site (Stoney et al., 1968; Gustafsson and Jankowska, 1976), and muscle activity evoked by the stimuli represents the motor output generated by these intraspinal sites (Perlmutter et al., 1998; Moritz et al., 2007). Therefore, if the initial limb state is represented within the spinal motor pathway, arm-posturedependent changes in the evoked twitch responses should be observed at a majority of intraspinal sites where stimulation is applied. Therefore, we electrically stimulated the cervical spinal cord of an anesthetized monkey while systematically changing the hand and arm position, and examined whether the evoked muscle responses changed or were stable under these conditions.

\section{Materials and Methods}

Three male rhesus macaques (monkey TE, $4.1 \mathrm{~kg}$; monkey TS, $5.0 \mathrm{~kg}$; monkey NE, $10.1 \mathrm{~kg}$ ) were included in this study. All procedures were performed in accordance with the National Institutes of Health Guidelines for the Care and Use of Laboratory Animals and were approved by the local ethics committee for primate research at the National Institute of Neuroscience.

Electrode implantation. Surgical operations were performed on each monkey to implant a floating microelectrode array (FMA; MicroProbes; Fig. 1D) and EMG wire electrodes. Surgery to implant the FMA was performed 2-4 weeks after the surgery to implant the EMG wires. All surgeries were performed using sevoflurane anesthesia $(1.5-2.5 \%$ in $2: 1$ $\mathrm{O}_{2} / \mathrm{N}_{2} \mathrm{O}$ ), and the monkey was artificially respired. Respiration rate was adjusted to keep end-tidal $\mathrm{CO}_{2}$ within $30-35 \mathrm{mmHg}$.

A 12-channel (monkeys TE and TS) or 32-channel (monkey NE) microelectrode array was implanted into the $\mathrm{C} 6$ segment of the spinal cord (Fig. 1C) to apply ISMS. The electrode length was $4 \mathrm{~mm}$ (monkey TE), 3 $\mathrm{mm}$ (monkey TS), or a mixture of 2,3 , and $4 \mathrm{~mm}(10,9$, and 13 electrodes each, respectively; monkey NE), and the impedance of each electrode ranged from 0.5 to $1.2 \mathrm{M} \Omega$. Within each array, electrodes were evenly spaced $(4 \mathrm{~mm})$.

First, the C3-T2 vertebrae were exposed bilaterally. Titanium screws were then inserted into the vertebrae transarticularly and tied with stainless steel wires on one side. A ground wire was wound around one of the stainless steel wires. The titanium screws and the stainless steel wires were 
Table 1. Angle of elbow and shoulder joints at each wrist position

\begin{tabular}{|c|c|c|c|c|c|c|c|}
\hline \multirow[b]{2}{*}{ Angle } & \multicolumn{7}{|l|}{ Wrist position } \\
\hline & 1 & 2 & 3 & 4 & 5 & 6 & 7 \\
\hline$\alpha$ & $28.2^{\circ}\left(8.5^{\circ}\right)$ & $16.1^{\circ}\left(14.2^{\circ}\right)$ & $61.3^{\circ}\left(5.9^{\circ}\right)$ & $53.6^{\circ}\left(6.3^{\circ}\right)$ & $31.2^{\circ}\left(9.3^{\circ}\right)$ & $74.9^{\circ}\left(9.1^{\circ}\right)$ & $49.0^{\circ}\left(8.1^{\circ}\right)$ \\
\hline$\beta$ & $127.3^{\circ}\left(13.3^{\circ}\right)$ & $150.3^{\circ}\left(24.0^{\circ}\right)$ & $67.6^{\circ}\left(3.9^{\circ}\right)$ & $81.0^{\circ}\left(5.7^{\circ}\right)$ & $121.8^{\circ}\left(14.0^{\circ}\right)$ & $46.4^{\circ}\left(4.2^{\circ}\right)$ & $89.5^{\circ}(9.3)$ \\
\hline$\theta$ & $0^{\circ}\left(0^{\circ}\right)$ & $20.4^{\circ}\left(0.9^{\circ}\right)$ & $0^{\circ}\left(0^{\circ}\right)$ & $30.7^{\circ}\left(1.9^{\circ}\right)$ & $49.8^{\circ}\left(2.1^{\circ}\right)$ & $56.3^{\circ}\left(3.8^{\circ}\right)$ & $71.0^{\circ}\left(3.2^{\circ}\right)$ \\
\hline
\end{tabular}

Mean ( \pm SD) data from three monkeys. See Figure $1 A$ for location of each angle $(\alpha, \beta, \theta)$.

cemented using dental acrylic. A C4-C5 laminectomy was performed and the dura matter removed to expose the dorsal surface of the spinal cord. Each microarray was held by a conventional manipulator (SM-11, Narishige) and fully inserted into the C6 segment of the spinal cord. Subsequently, the spinal cord was covered by artificial dura (ePTFE patch II, W.L. Gore \& Associates), and the laminectomy closed using dental acrylic. The connector of the electrode array, as well as the ground wire, was placed on the acrylic over the vertebrae and surrounded with a closeable chamber for protection.

For EMG recording, pairs of stainless steel wires (AS631, Cooner Wire) were implanted subcutaneously in the following muscles of the left arm: hand muscles: adductor pollicis, first dorsal interosseous (FDI), flexor digitorum superficialis, flexor carpi radialis (FCR), extensor carpi radialis; elbow muscles: brachioradialis, biceps brachii, long head of the triceps brachii, lateral head of the triceps brachii (monkeys TE and NE only); shoulder muscles: clavicular part of the deltoid, spine part of the deltoid, pectoralis major. Because the signals from the FDI of monkeys TE and NE were noisy, most likely because of a break in the electrode, the data from these muscles were discarded from the dataset. Consequently, EMGs recorded from 11 muscles were analyzed in each monkey.

Experimental procedure. Throughout the experiments, monkeys were anesthetized using ketamine (initial dose of $3.0 \mathrm{mg} / \mathrm{kg}$, i.m., supplemented at $2.3-3.8 \mathrm{mg} / \mathrm{kg} / \mathrm{h}$ ) and medetomidine hydrochloride (initial dose of $100 \mu \mathrm{g} / \mathrm{kg}$, i.m., supplemented at $30-50 \mu \mathrm{g} / \mathrm{kg}$ ) and laid prone on a table. Two padded poles were placed around the upper left (ipsilateral) arm at the shoulder joint to stabilize the position of the trunk during the experiment. The left wrist was secured just proximal to the styloid process of the radius in a specially designed swiveling U-shaped holder with an integrated multiaxis force sensor (Nano17, ATI Industrial Automation), which could then be fixed at one of seven points on a square grid with $8 \mathrm{~cm}$ intervals (Fig. 1A,B). The hand distal to the U-shaped holder was kept in a neutral position throughout the experiment. The joint angles of the shoulder $(\alpha)$ and elbow $(\beta)$, and that between the shoulder and wrist $(\theta)$ were measured in each animal and are listed in Table 1 . The right arm and hand were fully extended and placed next to the body, parallel to the body axis. Both legs were also fully extended.

First, we determined stimulation thresholds by delivering an ISMS train of 25 biphasic (negative-positive) pulses ( $400 \mu$ s duration at $50 \mathrm{~Hz}$ ) using an isolated stimulator (STG2008, Multi Channel Systems). Threshold currents for each electrode were defined as the minimum current to induce an output force at the left wrist by the 25 pulses. For monkeys TE and TS, this was done on the third and 22nd days after the FMA implantation. In the case of monkey NE, thresholds were obtained at the start of the experimental sessions.

Recording sessions were performed 6 (monkey TE), 67 (monkey TS), and 34 and $78 \mathrm{~d}$ (monkey NE) after the FMA implantations. In each session, $7,4,13$, and 6 electrodes, respectively, were selected because they showed the lowest stimulation thresholds, and these were used for the ISMSs. For monkey NE, different sets of electrodes were used for the two sessions. The same stimulus train as that used for the determination of threshold was used during the recording session, but we analyzed responses induced from the first stimulus exclusively as described below (responses to the other stimulus pulses were the subject of another study and are not analyzed in this paper). The pulse amplitude of stimulation for each electrode was set at just above the threshold current. The ISMS trains were delivered with an interval of $3 \mathrm{~s}$. After 6-20 trials were completed at one position, the wrist holder was moved to another point on the grid. The number of trials was consistent across each posture and each electrode, and the wrist position sequence and stimulation electrode order were randomized. ISMS responses were recorded as evoked EMGs and quantified. The EMGs were amplified $(\times 1500-5000)$, bandpass filtered $(5 \mathrm{~Hz}-3 \mathrm{kHz})$ using a multichannel differential amplifier (AB-611J and SS-1611, Nihon Kohden) and digitized at $10 \mathrm{kHz}$ (128-channel neural signal processor, Blackrock Microsystems).

Spinalization. To test how the ISMS responses changed following spinalization at the upper cervical level, we conducted a terminal experiment on monkey NE. Anesthesia was induced using ketamine $(7.5 \mathrm{mg} /$ $\mathrm{kg}$ ) and maintained with propofol $(1.5-2.5 \mathrm{mg} / \mathrm{kg} / \mathrm{h})$ and additionally sevoflurane $\left(0.5-3.0 \%\right.$ in $\left.2: 1 \mathrm{O}_{2} / \mathrm{N}_{2} \mathrm{O}\right)$. $\mathrm{C} 1$ and $\mathrm{C} 2$ vertebrae were exposed bilaterally and a laminectomy was performed at the $\mathrm{C} 2$ vertebra. We then measured ISMS responses pretransection as a control. Stimulus thresholds were determined as the minimum current required to induce force output at the wrist. ISMSs with two stimulus intensities (1.5 and 2 times the threshold current) were applied across the same seven postures as described above. After the control experiment, the spinal cord was transected at the $\mathrm{C} 2$ level by tearing nerve fascicles using forceps under microscopic vision. Gelatin sponge was inserted into the space between the cut ends of the spinal cord to confirm the transection. Following an interval of $30 \mathrm{~min}$, the ISMSs were applied again in the same procedure to the control experiment. After the experiment, the monkeys were deeply anesthetized with pentobarbital sodium $(35 \mathrm{mg} / \mathrm{kg})$ and perfused transcardially with heparin saline solution (heparin sodium $1 \mathrm{U} / \mathrm{ml}$ ), followed by $10 \%$ formalin. After fixation, the spinal cord was removed and the position of the implanted FMA electrode was confirmed.

Data analyses. Earlier studies used longer trains of stimuli (200-1000 $\mathrm{ms}$ ) at $25-70 \mathrm{~Hz}$ to evoke prolonged muscle force or movement (Bizzi et al., 1991; Giszter et al., 1993; Lemay and Grill, 2004). However, this approach has drawbacks (Strick, 2002). Using a long-train stimulus can cause current spread and directly induce synaptic activation well beyond the original stimulation site (Stoney et al., 1968; Gustafsson and Jankowska, 1976). As a result, the observed output may not be able to be specifically ascribed to a localized phenomenon of the stimulation site (Cheney et al., 2013). For this reason, we analyzed the response evoked exclusively by the first single-stimulus pulse and limited the current to the movement threshold.

Before testing the posture-dependent modulation of ISMS response, the EMG signal was preconditioned according to the following three steps: first, the EMGs were bandpass filtered $(10-1000 \mathrm{~Hz}$, Butterworth; order, 4); second, the stimulus artifact was eliminated by replacing the time range between stimulus onset to $1 \mathrm{~ms}$ (monkeys TE and TS) or $3 \mathrm{~ms}$ (monkey NE) with zeros; third, trials that showed a dominant electrocardiogram-like signal concomitant with the EMG waveform or dominant motor unit action potentials with spontaneous activity were visually detected and excluded from further analysis.

Then, using these preconditioned EMGs, we characterized the posture-dependent modulation of the ISMS response as follows: first, the voltage level of \pm 5 SDs of the signal from 30 to $10 \mathrm{~ms}$ before the stimulus (baseline period) was obtained using all trials recorded for each electrode-muscle pair and each posture; second, trials with a significant response were selected if any peaks and/or troughs exceeded this voltage continuously for $>1 \mathrm{~ms}$ within a detection time window $(0-20 \mathrm{~ms}$ after stimulus onset); third, the area and onset latency of the ISMS response in each trial was measured (area was defined as the sum of absolute value within the detection time window and was obtained for all trials with and without significant responses; for the trials with significant responses, their onset latency was defined as the earliest time point relative to the stimulus onset at which the signal crossed the threshold voltages); finally, the posture-dependent modulation of the obtained area and onset laten- 
cies was tested using one-way ANOVA only for electrode-muscle pairs exhibiting significant responses in $\geq 1$ posture.

\section{Results}

In three monkeys, we examined the ISMSinduced response for a total of 330 electrode-muscle pairs $(77,44$, and 209 pairs in monkeys TE, TS, and NE, respectively). Among them, 202 (202 of 330; 61\%) pairs exhibited significant EMG responses (63 of $77 ; 82 \%$ for monkey TE; 29 of $44 ; 66 \%$ for monkey TS; and 110 of 209; 53\% for monkey NE). The threshold current for each FMA electrode ranged from 50 to $110 \mu \mathrm{A}$ (monkey TE), from 100 to $200 \mu \mathrm{A}$ (monkey TS), and from 80 to $410 \mu \mathrm{A}$ (monkey NE), respectively. The effect of the position of the electrode tip was examined in monkey NE, who had been implanted with an array consisting of electrodes with different lengths. Threshold currents for the three different lengths $[416 \pm 57.7 \mu \mathrm{A}$ for $2 \mathrm{~mm}(n=5), 282.5 \pm$ 29.8 for $3 \mathrm{~mm}(n=4), 322.5 \pm 82.6$ for 4 $\mathrm{mm}(n=4)]$ were significantly different $\left(F_{(2,10)}=5.93, p<0.02\right)$, suggesting that the deeper electrodes, which were located more ventrally, activated motoneuron pools more directly than shallower electrodes. No difference was found in the rostral-caudal ( $322.0 \pm 81.0$ vs $361.25 \pm$ $83.0 \mu \mathrm{A}, t_{(11)}=0.83, p=0.21, t$ test) or medial-lateral $\left(308.3 \pm 42.6\right.$ vs $378.5 \pm 95.1 \mu \mathrm{A}, t_{(11)}=1.66, p=$ $0.06, t$ test) positions.

\section{Posture-dependent modulation of ISMS-evoked responses}

We first tested whether the ISMS-evoked EMG responses in arm muscles showed modulation that was dependent on forelimb posture. One example of an electrode-muscle pair is shown in Figure 2A (channel 11-FDI pair from monkey TS). In this case, a significant EMG response in the FDI muscle was observed in all seven postures, and the size of the response differed among the postures. The response was largest when the hand was positioned closer to the forehead (7) and smallest when the hand was in the center of the work field (4). This postural dependency was confirmed statistically (ANOVA, $F_{(6,119)}=19.7, p<0.01$; Fig. $2 B$ ). As well as the amplitude, the onset latency was also modulated depending on the forelimb posture (Fig. 2C). We judged the response to be posture dependent if either the amplitude or the onset latency showed significant changes across postures. Among the electrode-muscle pairs that exhibited a significant ISMSevoked response, a majority (80\%) showed significant postural dependency on either amplitude or latency (Table 2). The reproducibility of postural dependency was confirmed using 12 electrode-muscle pairs that showed postural dependency on the same recording day (monkey NE). Among these pairs, a majority $(83 \% ; 10$ of 12$)$ showed no difference in the pattern of postural dependency between the first and second set of experiments $(p<$ 0.01 , two-way ANOVA) suggesting that postural dependency is a reproducible phenomenon.

Next, we examined the possibility of whether the postural dependency was induced by the experimental artifact. First, we
Table 2. Proportion of the responses where amplitude and/or onset latency were modulated dependent on limb posture

\begin{tabular}{|c|c|c|c|}
\hline & Monkey TE & Monkey TS & Monkey NE \\
\hline Modulation & $87 \%$ (55 of 63 ) & $86 \%$ (25 of 29 ) & $74 \%$ (81 of 110$)$ \\
\hline Amplitude and latency & $71 \%$ (39 of 55) & $68 \%$ (17 of 25 ) & $57 \%$ (46 of 81 ) \\
\hline Amplitude only & $27 \%$ (15 of 55$)$ & $32 \%$ (8 of 25 ) & $41 \%$ (33 of 81 ) \\
\hline Latency only & $2 \%$ (1 of 55 ) & $0 \%(0$ of 25$)$ & $2 \%(2$ of 81$)$ \\
\hline
\end{tabular}

Over $70 \%$ of responses represented significant modulation in all the three monkeys. Both the response amplitude and onset latency were modulated in a majority of the responses that displayed posture dependency. The numbers in parentheses show the number of the responses.

analyzed the influence of depth of anesthesia on the ISMS output. Through six electrodes in monkey NE, ISMSs were applied on posture 4 twice, at the beginning and end of the usual experiment, and the depth of anesthesia was evaluated by measuring the heart rate of the monkey. Mean heart rates were $68.8 \pm 0.7$ beats per minute $(\mathrm{bpm})$ during the first measurement and $72.7 \pm 0.4 \mathrm{bpm}$ during the second measurement, and were significantly different $\left(t_{(25)}=16.6, p<0.01, t\right.$ test $)$. Thus, anesthesia was deeper during the first measurement. However, mean differences between the response amplitudes and the onset latency during the first and second measurements were not significant (amplitude, $-1.50 \pm$ $7.94 \mu \mathrm{Vs}, t_{(36)}=1.15, p=0.26$; latency, $0.18 \pm 1.80 \mathrm{~ms}, t_{(31)}=$ $0.58, p=0.57$; paired $t$ test). Therefore, the responses may not have been affected by depth of anesthesia. Second, we examined the possibility that the posture-dependent modulation of the ISMS output could be ascribed to the subtle relocation of EMG wires during the experiment. This is unlikely because our intramuscular wires were directly sutured into each muscle and the order of stimulation to each electrode was randomized. In addi- 
A

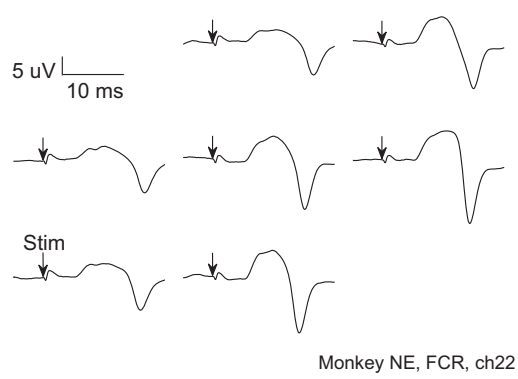

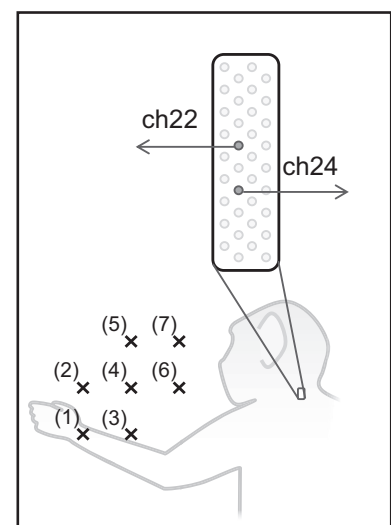

B

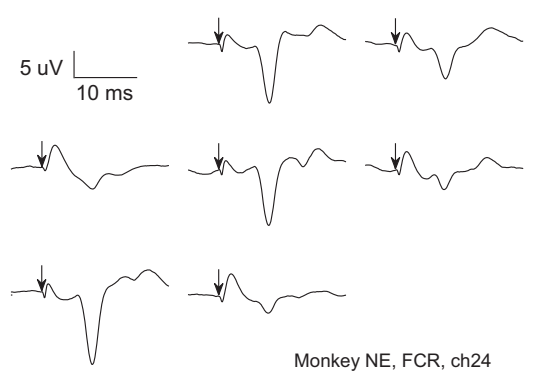

Figure 3. Different patterns of posture dependency. $\boldsymbol{A}$, The EMG response of FCR evoked by stimulations through channel 22 (ch22; monkey NE) was modulated depending on the limb posture. It was large in postures 3 and 6 , and small in postures 1,2 , and 5 . The arrows indicate the timing of stimuli. $\boldsymbol{B}$, The same muscle as $\boldsymbol{A}$ with a different stimulation electrode [channel 24 (ch24)]. The induced EMG was also modulated depending on the posture, but was large in postures 1,4 , and 5 , and small in postures 2,3 , and 6 .

tion, data shown in Figure 3 further suggest that this situation is not likely. If the posture-dependent modulation were ascribed to the relocation of the electrode in different postures, one might expect the same patterns of posture-dependent modulations of a particular muscle EMG output from all stimulation electrodes. However, this figure shows different patterns of the posture dependency observed in responses recorded from the same muscle (FCR) but evoked by different stimulation electrodes (Fig. 3A, ch22, $B$, ch24, inset). The response amplitude evoked by channel 22 (Fig. 3A) was higher in postures 3 (105.8 $\mu \mathrm{Vs})$ and 6 (120.2 $\mu \mathrm{Vs})$, and smaller in postures $1(70.0 \mu \mathrm{Vs}), 2(66.6 \mu \mathrm{Vs})$, and 5 $(67.4 \mu \mathrm{Vs})$. The amplitude evoked by channel 24 , however (Fig. $3 B)$, was largest in postures $1(76.8 \mu \mathrm{Vs}), 4(58.4 \mu \mathrm{Vs})$, and 5 $(69.2 \mu \mathrm{Vs})$, and smaller in postures $2(39.2 \mu \mathrm{Vs}), 3(33.8 \mu \mathrm{Vs})$, and $6(45.2 \mu \mathrm{Vs})$. The patterns of modulation in the responses in the FCR were significantly different between electrodes in channels 22 and $24\left(F_{(6,266)}=31.76, p<0.01\right.$, two-way ANOVA). This difference in modulation pattern continued across many of the stimulating electrodes. Therefore, posture dependency could not be ascribed to instability of the EMG recording electrodes.

We also examined the possibility that the postural dependency of ISMS output might be a secondary effect from the differing background activity of EMGs in different wrist positions. For this objective, we measured the SD of the baseline period as an index of background EMG activity for each trial $(n=183)$ with significant responses and examined their size for each wrist position. We found a postural difference in $27 \%(n=51)$ of electrode-muscle pairs. This probability was significantly smaller than that of the postural dependency of ISMS responses $(n=155,83 \%)$. Therefore, the effect of baseline EMG difference on the postural dependency of ISMS responses was minor. Overall, we conclude that the postural dependency of ISMS response was not an epiphenomenon caused by these experimental constraints.

\section{Characterization of posture dependency of ISMS output}

If this posture dependency has a role in a specific movement of the upper limb, it should be observed frequently in a specific muscle or muscle groups. For example, the contribution to grasping should be represented predominantly in distal muscles and the contribution to reaching movement should be represented in proximal muscles. To test this possibility, we examined whether posture dependency could be determined by specific characteristics of specific muscles (Fig. 4A,B). Target muscles for EMG recording were categorized according to (1) their location within
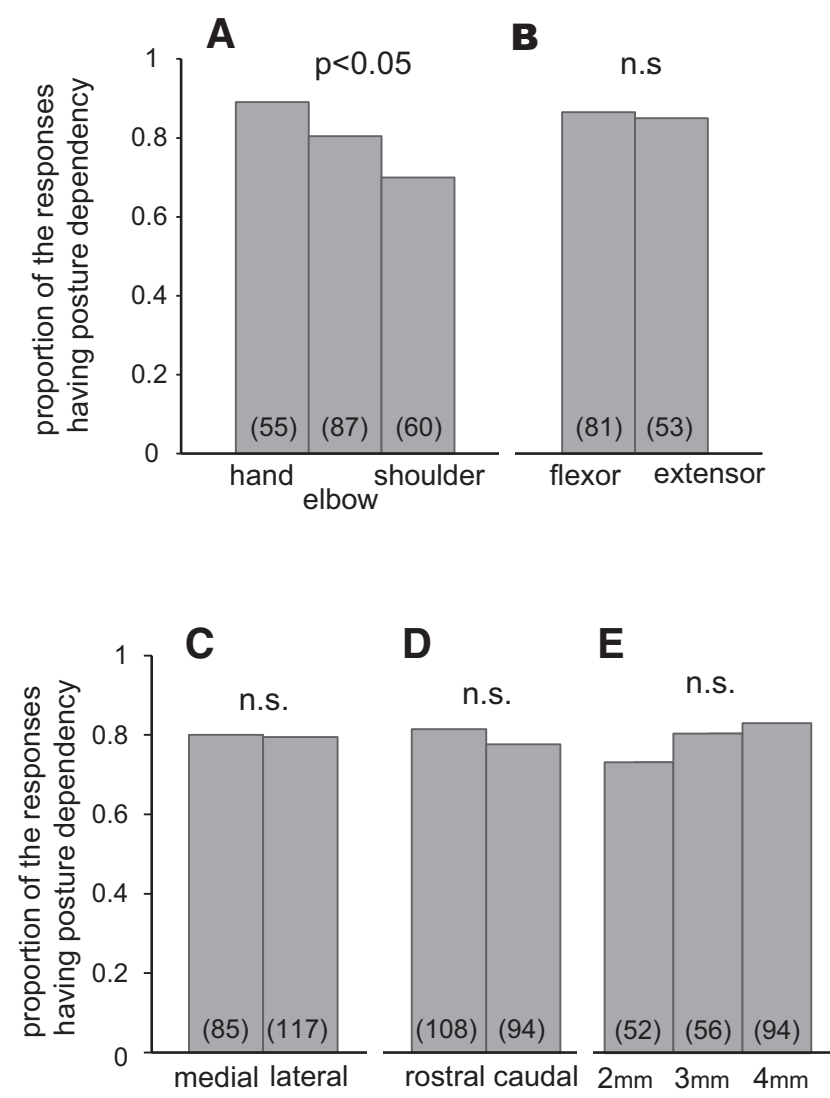

Figure 4. $A-E$, Distribution of posture dependency based on the location and function of each muscle $(\boldsymbol{A}, \boldsymbol{B})$ and the location of the stimulation electrodes within the spinal cord $(\boldsymbol{C}-\boldsymbol{E}) \cdot \boldsymbol{A}$, The proportion of responses with posture dependency was significantly different depending on the body parts containing the muscles $\left(\chi_{(2)}^{2}=6.52, p<0.05, \chi^{2}\right.$ test). $B$, No significant difference was detected based on the physiological function of muscles. Each intraspinal site that was activated by ISMS was categorized according to its $(\boldsymbol{C})$ mediolateral location, (D) rostrocaudal location, and (E) depth (length of each electrode). No significant effect was observed based on the location of each intraspinal site ( $\chi^{2}$ test). The numbers in parentheses show the number of responses.

the body or (2) their anatomical function, as shown in Table 3. The proportions of the responses that had a posture dependency were compared using a $\chi^{2}$ test $(\alpha=0.05)$ within these categories. We found a significant effect of body part. The proportion of 
Table 3. Categories of the target muscles for EMG

\begin{tabular}{lll}
\hline Muscle & Body part & Anatomical function \\
\hline Adductor pollicis & Hand & - \\
FDI & Hand & - \\
Flexor digitorum superficialis & Hand & Flexor \\
FCR & Hand & Flexor \\
Extensor carpi radialis & Hand & Extensor \\
Brachioradialis & Elbow & Flexor \\
Biceps & Elbow & Flexor \\
Triceps (lateral) & Elbow & Extensor \\
Triceps (long) & Elbow & Extensor \\
Deltoid (clavicle) & Shoulder & - \\
Deltoid (spine) & Shoulder & - \\
Pectoralis major & Shoulder & - \\
\hline
\end{tabular}

ADP, FDI, and three shoulder muscles were excluded from this categorization according to anatomical function because it was difficult to categorize these muscles as flexors or extensors. Note that the terms "flexor" and "extensor" defined anatomical functions, but not physiological functions of responsible joints.

responses showing posture dependency in the hand, elbow, and shoulder muscles were 89,81 , and 70\%, respectively (Fig. 4A). This difference depending on body part was statistically significant $\left(\chi_{(2)}^{2}=6.52, p<0.05, \chi^{2}\right.$ test $)$, suggesting that the probability of finding a posture-dependent response to ISMS was different depending on the location of the target muscle within the body; a larger portion of hand muscles, compared to proximal muscles, showed posture dependency. In contrast, we found no significant effect of the physiological function of the target muscles. There was no difference in the proportion $\left(\chi_{(1)}^{2}=0.06\right.$, $p=0.81, \chi^{2}$ test) between the flexors $(86 \%)$ and extensors $(85 \%$; Fig. $4 B$ ). In summary, we found posture dependency predominantly in the distal finger muscles, but no difference was found between physiological flexor and extensor muscles.

To test whether the generation of posture dependency could be ascribed to a specific group of spinal neurons or axons, we examined the topographic organization of the intraspinal sites from which the posture dependency was generated. For this purpose, we grouped the stimulated intraspinal sites using the location of each electrode within the array relative to (1) its mediolateral axis, (2) its rostrocaudal axis, and (3) its length. As shown in Figure $4 C-E$, we found no significant effects based on the location of the stimulation electrodes. The proportions were as follows: (1) 80 and $80 \%$ for the medial and lateral halves $\left(\chi_{(1)}^{2}\right.$ $=0.01, p=0.92, \chi^{2}$ test); (2) 82 and $78 \%$ for the rostral and caudal halves $\left(\chi_{(1)}^{2}=0.45, p=0.51, \chi^{2}\right.$ test); and (3) 73, 80, and $83 \%$ for the 2,3 , and $4 \mathrm{~mm}$ electrodes $\left(\chi_{(2)}^{2}=2.05, p=0.36, \chi^{2}\right.$ test). Consequently, the nontopographical organization of intraspinal sites generating posture dependency may suggest that it could involve multiple types of spinal neurons.

\section{Posture dependency represents an intraspinal mechanism}

A potential mechanism underlying posture dependency could be posture-driven changes in the ensemble of afferent inputs (both direct and indirect) from the arm and shoulder; the excitability of the sites being stimulated by ISMS would then be affected by them. The excitability of intraspinal sites could be modulated by peripheral afferents, either via a direct pathway (e.g., a segmental reflex pathway; Hultborn, 2006) or a more indirect pathway through the brainstem (Drew et al., 1996) and cortex (Fromm and Evarts, 1982). To dissociate these direct and indirect mechanisms for generating posture dependency, the spinal cord was transected at the upper cervical level (C2), allowing a comparison in the posture dependency of the ISMS effect before and after the transection in monkey NE. Figure $5 A, B$ shows a typical example.
We found that posture dependency remained even after the transection at $\mathrm{C} 2$. In these examples, responses in a single muscle $(A$, deltoid; $B$, triceps lateralis) evoked by stimulation through a single electrode (medial, caudal, $3 \mathrm{~mm}$ ) clearly showed posture dependency both before and after transection. Moreover, the patterns of posture dependency are strikingly similar before (gray) and after (black) the transection. Before the transection, 113 responses were found in 132 recorded EMGs. Among these, $91(80.5 \%)$ showed posture dependency before the transection, and an equivalent proportion of pairs $(92,78.0 \%)$ still showed this posture dependency following the transection. Because this change in proportion was not statistically significant $\left(\chi_{(1)}^{2}=0.23\right.$, $p=0.63, \chi^{2}$ test), we can conclude that posture dependency is largely generated through an intraspinal mechanism and that the effect from cortex and brainstem is minor, at least under the current experimental conditions. This conclusion is also supported by the observation that the electrode-muscle pairs that showed responses before and after the spinal transection were the same pairs in most cases ( $n=79$; Fig. $5 C$, inset). Additionally, the preferential distribution of the occurrence of posture dependency in the hand muscles (Fig. $4 A$ ) was also preserved after spinalization (Fig. 5D). This result suggests that this hand dominance might also be generated through intraspinal mechanisms.

\section{Discussion}

In this study, we found that the sizes and latencies of the twitch responses induced by single-pulse ISMS were modulated depending on the limb posture. This modulation remained after the transection of the spinal cord at C2, suggesting that the posture dependency of ISMS responses was induced by intraspinal mechanisms. The modulation of ISMS-induced motor output by limb posture has been reported in several studies. For example, the force and EMG output of lower limb muscles induced by the microstimulation of the frog's lumbar cord is known to be modulated depending on the initial limb posture (Bizzi et al., 1991; Giszter et al., 1993). A similar phenomenon has also been reported in the spinal cord of cats (Lemay and Grill, 2004) and the motor cortex in monkeys (Graziano et al., 2002; Van Acker et al., 2013). Our findings extend these observations to the cervical spinal cord of primates, and add the proposal that the spinal neural mechanism responsible for posture dependency could also play a key role in the primate for controlling arm and hand movement.

Ample evidence suggests that the ensemble of afferent activity from muscle, joint, and cutaneous receptors is essential in shaping a sense of limb posture (kinesthesia). For example, local anesthesia impairs the perception of limb position (Edin and Johansson, 1995) and tendon vibration generates a strong postural illusion (Collins and Prochazka, 1996). Successful reconstruction of the limb's kinematic state via the ensemble activity of peripheral nerves (Stein et al., 2004; Umeda et al., 2012) raises the possibility that a part of kinesthesia could emerge at any level of postsynaptic cells from multiple afferents, including spinal INs and motoneurons (Bosco and Poppele, 2001, 2003). Therefore, it is likely that an ensemble of primary afferent fibers are also recruited in different modes by different arm postures, and that these differences could be also reflected in the excitability of postsynaptic neurons in the spinal cord, including spinal INs and motoneurons. The posture dependency of the ISMS response, consequently, could reflect that a different mode of ensemble activity of the primary afferents also affects the excitability of spinal motor output system.

The modulation of spinal motor output by afferent input may not be exclusively accounted for by the intraspinal mechanism. 


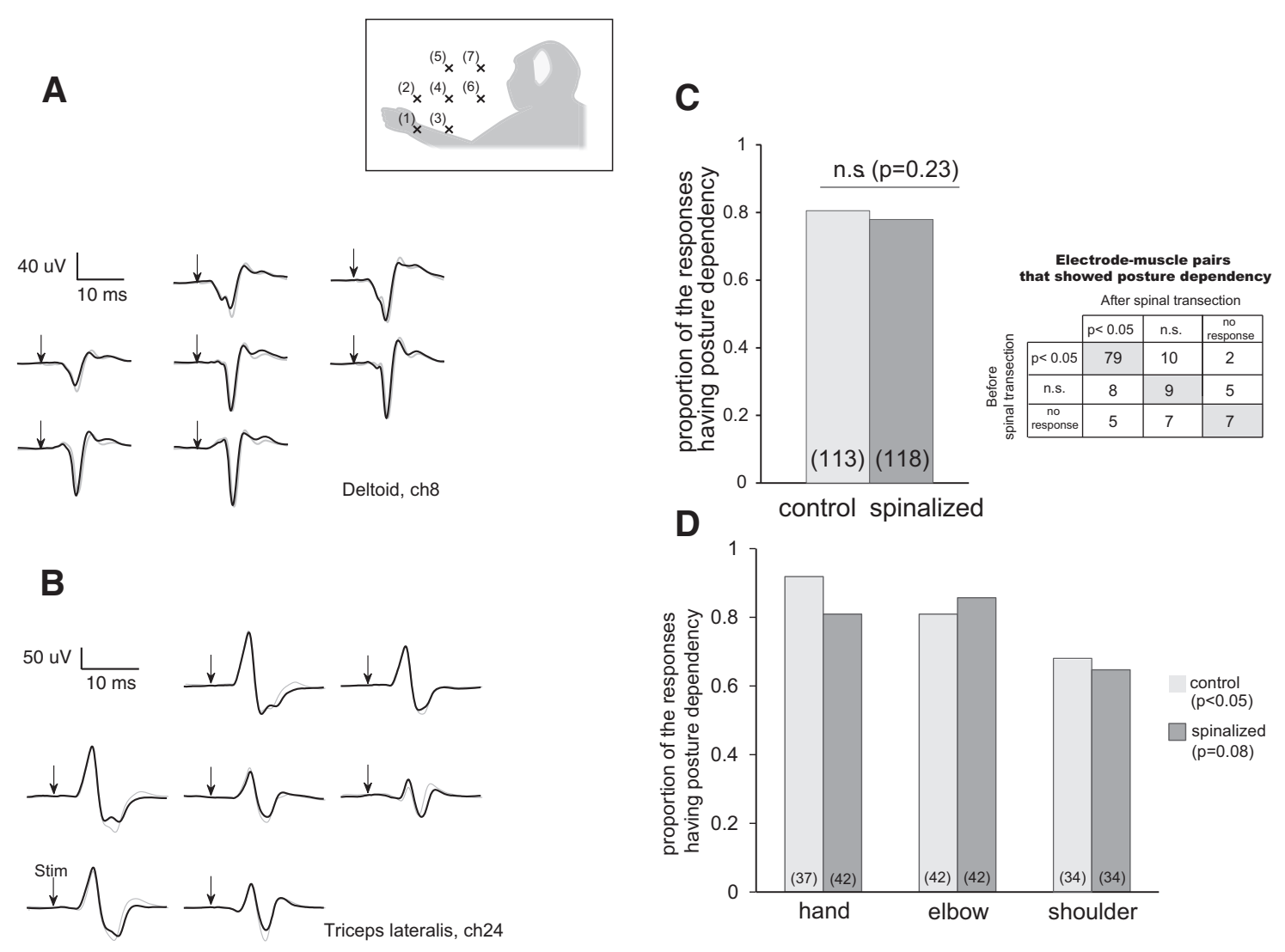

Figure 5. Effect of spinalization. $A, B$, Modulation patterns of the responses of the lateral head of the deltoid evoked by stimulation through channel $8(A, c h 8)$ or that of the triceps brachii evoked by stimulation through channel 24 ( $\boldsymbol{B}, \mathrm{ch} 24)$ before (gray) or after (black) spinalization. Modulation remained after spinalization. The arrows indicate stimulus timing. $\boldsymbol{C}$, The proportion of the responses with posture dependency was not significantly different $\left(\chi_{(1)}^{2}=0.23, p=0.63, \chi^{2}\right.$ test). The numbers in parentheses show the number of responses. Inset table shows the number of electrode-muscle pairs that showed responses before and after the spinal transection. $p<0.05$, Pairs showed significant postural dependency; n.s., pairs without significant postural dependency; no response, pairs that showed no significant peak in any of the seven postures. $\boldsymbol{D}$, The difference across body parts was nearly significant following spinalization $\left(p=0.08, \chi^{2}\right.$ test), and we found a similar tendency for responses to be lower in shoulder muscles. The numbers in parentheses show the number of responses. A similar probability distribution shown in Figure $4 A$ was reproduced before the transection $\left(p<0.05, \chi^{2}\right.$ test). The pattern of distribution of posture dependency was similar before and after transection.

For example, neurons in the primary motor cortex, including corticospinal neurons, have been shown to exhibit a robust response to stimuli applied to the periphery (Asanuma and Arissian, 1984). Deafferentation (Jiang et al., 2013) of forelimb somatic afferents is known to introduce a rapid change in cortical sensory-motor representation (Jiang et al., 2013). However, as shown in Figure 5, the posture dependency of spinal motor output was sustained even after transection at the $\mathrm{C} 2$ level. Therefore, we can conclude that the mechanism underlying the posture dependency of a stimulusevoked response cannot be ascribed completely to these supraspinal systems; rather, it could reside within the spinal cord, e.g., within the segmental or propriospinal reflex pathways.

Spinal neurons are known to receive convergent input from peripheral afferents with different modalities and receptive fields (Baldissera et al., 1981; Hultborn, 2006). Sites of convergence could be on the intraspinal terminal of primary afferents ( $\mathrm{Ru}$ domin and Schmidt, 1999), INs (Jankowska, 1992; Liu et al., 2010), or motoneurons (Scott and Mendell, 1976). Because ISMS could activate any of these sites (Moritz et al., 2007), the result showing posture dependency of spinal motor output regardless of the stimulation location (Fig. 4C-E) may suggest that most of these sites of convergence are likely to contribute to generating this effect.

Interestingly, the posture dependency of spinal motor output was observed preferentially in the hand muscles (Figs. 4A, 5D). Although the neural mechanism underlying this hand preference is not clear in our experiment, it could have some consequence in understanding the cortical control of hand movements. It has been shown that the majority of stimulation sites in monkey motor cortex evokes movements of the thumb and fingers (Asanuma and Rosén, 1972; Kwan et al., 1978) and stimulation of the motor cortex facilitates distal muscles at $60 \%$ of sites (Park et al., 2004). Based on these studies, it is possible that part of the ISMS response in the finger and thumb muscles was generated by stimulating the intraspinal axon of corticospinal cells (Moritz et al., 2007). Then, biased distribution of the posture dependency to the finger and thumb muscle suggests that corticospinal signals generating volitional movement could be affected at the spinal level by the initial limb posture. For example, posture-dependent ensemble input from primary afferents could modulate the excitability around the intraspinal terminal or postsynaptic cells of the corticospinal tract in the spinal cord. The modulation of both spinal reflex and descending motor output of the finger muscle when changing shoulder position in human participants (Dominici et al., 2005) seems to support this hypothesis. We suggest that the modulation of descending motor commands to the spinal cord by posture dependency could be a mechanism that adjusts cortical motor commands depending on the initial state of the arm and hand during voluntary movement (Grillner, 2006). The original descending command could go through this "posturedependent filter" at the spinal cord, and the final motor command to individual motoneuron pools and thus muscles could be 
generated through this filter. These "indirect" pathways could be functioning as part of the control of volitional movement, in parallel with more direct control, such as that via the corticomotoneuronal pathway (Lemon, 2008). To fully support this hypothesis and elucidate the neural correlate of the posture dependency of spinal excitability, further experiments comparing the posture dependency of spinal cord and motor cortex in both anesthetized and awake, active monkeys are needed. In fact, it is highly possible that the postural dependency of spinal motor output reported in this paper is masked or modulated by the higher level of activity in the brain and descending tract. Elucidating the mechanism and relevance of the mode of modulation on the postural dependency of spinal motor output by these descending commands will be a key issue for our understanding of the neural control of voluntary movements.

Recently, spinal cord stimulation has been used in neural prostheses. It has been shown that ISMS can generate functional movements, such as walking (Mushahwar et al., 2000) or grasping (Moritz et al., 2007; Zimmermann et al., 2011) in animals, without descending input. In human patients with complete paraplegia, epidural stimulation of the spinal cord has also been shown to facilitate standing and walking (Harkema et al., 2011; Angeli et al., 2014). So far, however, most applications of ISMS use preset stimulus parameters (amplitude and frequency of stimulus train), and this could induce potential problems in clinical applications. As introduced in this paper, ISMS using the same parameters could evoke significantly different limb movements depending on the initial posture of the limb. Therefore, reliable and reproducible neural prostheses using ISMS may not be achieved without knowing the relationship between the excitability of neurons around the stimulating electrode and the limb posture when ISMS is applied. Setting an initial value corresponding to the resting posture is also a challenge in a cortically controlled brain-machine interface (Velliste et al., 2014). Determining the neural mechanism that induces posture dependency during ISMS, therefore, should also advance the clinical application of ISMS for recovery from motor impairments.

\section{References}

Angeli CA, Edgerton VR, Gerasimenko YP, Harkema SJ (2014) Altering spinal cord excitability enables voluntary movements after chronic complete paralysis in humans. Brain 137:1394-1409. CrossRef Medline

Asanuma H, Arissian K (1984) Experiments on functional role of peripheral input to motor cortex during voluntary movements in the monkey. J Neurophysiol 52:212-227. Medline

Asanuma H, Rosén I (1972) Functional role of afferent inputs to the monkey motor cortex. Brain Res 40:3-5. CrossRef Medline

Baldissera F, Hultborn H, Illert M (1981) Integration in spinal neuronal systems. In: Handbook of physiology (Brooks VB, ed), pp 509-595. Bethesda, Maryland: American Physiological Society.

Bizzi E, Mussa-Ivaldi FA, Giszter S (1991) Computations underlying the execution of movement: a biological perspective. Science 253:287-291. CrossRef Medline

Bosco G, Poppele RE (2001) Proprioception from a spinocerebellar perspective. Physiol Rev 81:539-568. Medline

Bosco G, Poppele RE (2003) Modulation of dorsal spinocerebellar responses to limb movement. II. Effect of sensory input. J Neurophysiol 90:3372-3383. CrossRef Medline

Cheney PD, Griffin DM, Van Acker GM 3rd (2013) Neural hijacking: action of high-frequency electrical stimulation on cortical circuits. Neuroscientist 19:434-441. CrossRef Medline

Collins DF, Prochazka A (1996) Movement illusions evoked by ensemble cutaneous input from the dorsum of the human hand. J Physiol 496:857871. CrossRef Medline

Dominici F, Popa T, Ginanneschi F, Mazzocchio R, Rossi A (2005) Corticomotoneuronal output to intrinsic hand muscles is differentially influ- enced by static changes in shoulder positions. Exp Brain Res 164:500-504. CrossRef Medline

Drew T, Cabana T, Rossignol S (1996) Responses of medullary reticulospinal neurones to stimulation of cutaneous limb nerves during locomotion in intact cats. Exp Brain Res 111:153-168. Medline

Edin BB, Johansson N (1995) Skin strain patterns provide kinaesthetic information to the human central nervous system. J Physiol 487:243-251. CrossRef Medline

Fromm C, Evarts EV (1982) Pyramidal tract neurons in somatosensory cortex: central and peripheral inputs during voluntary movement. Brain Res 238:186-191. CrossRef Medline

Giszter SF, Mussa-Ivaldi FA, Bizzi E (1993) Convergent force fields organized in the frog's spinal cord. J Neurosci 13:467-491. Medline

Graziano MS, Taylor CS, Moore T (2002) Complex movements evoked by microstimulation of precentral cortex. Neuron 34:841-851. CrossRef Medline

Grillner S (2006) Biological pattern generation: the cellular and computational logic of networks in motion. Neuron 52:751-766. CrossRef Medline

Grillner S, Rossignol S (1978) Contralateral reflex reversal controlled by limb position in the acute spinal cat injected with clonidine i.v. Brain Res 144:411-414. CrossRef Medline

Gustafsson B, Jankowska E (1976) Direct and indirect activation of nerve cells by electrical pulses applied extracellularly. J Physiol 258:33-61. CrossRef Medline

Harkema S, Gerasimenko Y, Hodes J, Burdick J, Angeli C, Chen Y, Ferreira C, Willhite A, Rejc E, Grossman RG, Edgerton VR (2011) Effect of epidural stimulation of the lumbosacral spinal cord on voluntary movement, standing, and assisted stepping after motor complete paraplegia: a case study. Lancet 377:1938-1947. CrossRef Medline

Holstege G, Kuypers HG (1982) The anatomy of brain stem pathways to the spinal cord in cat. A labeled amino acid tracing study. Prog Brain Res 57:145-175. CrossRef Medline

Holstege G, Tan J (1988) Projections from the red nucleus and surrounding areas to the brainstem and spinal cord in the cat. An HRP and autoradiographical tracing study. Behav Brain Res 28:33-57. CrossRef Medline

Hultborn H (2006) Spinal reflexes, mechanisms and concepts: from Eccles to Lundberg and beyond. Prog Neurobiol 78:215-232. CrossRef Medline

Jankowska E (1992) Interneuronal relay in spinal pathways from proprioceptors. Prog Neurobiol 38:335-378. CrossRef Medline

Jiang YQ, Williams PT, Martin JH (2013) Rapid and persistent impairments of the forelimb motor representations following cervical deafferentation in rats. Eur J Neurosci 38:3702-3711. CrossRef Medline

Kwan HC, MacKay WA, Murphy JT, Wong YC (1978) Spatial organization of precentral cortex in awake primates. II. Motor outputs. J Neurophysiol 41:1120-1131. Medline

Lemay MA, Grill WM (2004) Modularity of motor output evoked by intraspinal microstimulation in cats. J Neurophysiol 91:502-514. Medline

Lemon RN (2008) Descending pathways in motor control. Annu Rev Neurosci 31:195-218. CrossRef Medline

Liu TT, Bannatyne BA, Jankowska E, Maxwell DJ (2010) Properties of axon terminals contacting intermediate zone excitatory and inhibitory premotor interneurons with monosynaptic input from group I and II muscle afferents. J Physiol 588:4217-4233. CrossRef Medline

Lundberg A, Voorhoeve P (1962) Effects from the pyramidal tract on spinal reflex arcs. Acta Physiol Scand 56:201-219. CrossRef Medline

Lundberg A, Norrsell U, Voorhoeve P (1962) Pyramidal effects on lumbosacral interneurones activated by somatic afferents. Acta Physiol Scand 56:220-229. CrossRef Medline

Morecraft RJ, Ge J, Stilwell-Morecraft KS, McNeal DW, Pizzimenti MA, Darling WG (2013) Terminal distribution of the corticospinal projection from the hand/arm region of the primary motor cortex to the cervical enlargement in rhesus monkey. J Comp Neurol 521:4205-4235. CrossRef Medline

Moritz CT, Lucas TH, Perlmutter SI, Fetz EE (2007) Forelimb movements and muscle responses evoked by microstimulation of cervical spinal cord in sedated monkeys. J Neurophysiol 97:110-120. CrossRef Medline

Mushahwar VK, Collins DF, Prochazka A (2000) Spinal cord microstimulation generates functional limb movements in chronically implanted cats. Exp Neurol 163:422-429. CrossRef Medline

Park MC, Belhaj-Saïf A, Cheney PD (2004) Properties of primary motor 
cortex output to forelimb muscles in rhesus macaques. J Neurophysiol 92:2968-2984. CrossRef Medline

Perlmutter SI, Maier MA, Fetz EE (1998) Activity of spinal interneurons and their effects on forearm muscles during voluntary wrist movements in the monkey. J Neurophysiol 80:2475-2494. Medline

Prut Y, Fetz EE (1999) Primate spinal interneurons show pre-movement instructed delay activity. Nature 401:590-594. CrossRef Medline

Ralston DD, Ralston HJ 3rd (1985) The terminations of corticospinal tract axons in the macaque monkey. J Comp Neurol 242:325-337. CrossRef Medline

Rudomin P, Schmidt RF (1999) Presynaptic inhibition in the vertebrate spinal cord revisited. Exp Brain Res 129:1-37. CrossRef Medline

Scott JG, Mendell LM (1976) Individual EPSPs produced by single triceps surae Ia afferent fibers in homonymous and heteronymous motoneurons. J Neurophysiol 39:679-692. Medline

Scott SH (2004) Optimal feedback control and the neural basis of volitional motor control. Nat Rev Neurosci 5:532-546. CrossRef Medline

Stein RB, Weber DJ, Aoyagi Y, Prochazka A, Wagenaar JB, Shoham S, Normann RA (2004) Coding of position by simultaneously recorded sensory neurones in the cat dorsal root ganglion. J Physiol 560:883-896. CrossRef Medline

Stoney SD Jr, Thompson WD, Asanuma H (1968) Excitation of pyramidal tract cells by intracortical microstimulation: effective extent of stimulating current. J Neurophysiol 31:659-669. Medline
Strick PL (2002) Stimulating research on motor cortex. Nat Neurosci 5:714-715. CrossRef Medline

Takei T, Seki K (2010) Spinal interneurons facilitate coactivation of hand muscles during a precision grip task in monkeys. J Neurosci 30:1704117050. CrossRef Medline

Takei T, Seki K (2013) Spinal premotor interneurons mediate dynamic and static motor commands for precision grip in monkeys. J Neurosci 33: 8850-8860. CrossRef Medline

Umeda T, Seki K, Sato MA, Nishimura Y, Kawato M, Isa T (2012) Population coding of forelimb joint kinematics by peripheral afferents in monkeys. PLoS One 7:e47749. CrossRef Medline

Van Acker GM 3rd, Amundsen SL, Messamore WG, Zhang HY, Luchies CW, Kovac A, Cheney PD (2013) Effective intracortical microstimulation parameters applied to primary motor cortex for evoking forelimb movements to stable spatial end points. J Neurophysiol 110:1180-1189. CrossRef Medline

Velliste M, Kennedy SD, Schwartz AB, Whitford AS, Sohn JW, McMorland AJ (2014) Motor cortical correlates of arm resting in the context of a reaching task and implications for prosthetic control. J Neurosci 34:60116022. CrossRef Medline

Zimmermann JB, Seki K, Jackson A (2011) Reanimating the arm and hand with intraspinal microstimulation. J Neural Eng 8:054001. CrossRef Medline 